\title{
Core Elements of Shared Decision-making for Women Considering Breast Cancer Screening: Results of a Modified Delphi Survey
}

\author{
Kenneth D. Croes, $P h D^{7}$, Nathan R. Jones, $P h D^{7}$, Lori L. DuBenske, PhD², \\ Sarina B. Schrager, MD, MS ${ }^{2}$, Jane E. Mahoney, MD², Terry A. Little, $M S^{2}$, and \\ Elizabeth S. Burnside, MD, MPH, MS $S^{2,3}$ \\ 'University of Wisconsin Survey Center, Madison, WI, USA; '²niversity of Wisconsin-Madison, School of Medicine and Public Health, Madison, WI, USA; \\ 3 , Madison, USA.
}

BACKGROUND: The United States Preventive Services Task Force recommends individualized breast cancer screening for average-risk women before age 50, advised by risk assessment and shared decision-making (SDM). However, the foundational principles of this recommendation that would inform decision support tools for patients and primary care physicians at the point of care have not been codified. Determining the core elements of SDM for breast cancer screening as valued by patients and primary care providers (PCPs) is necessary for implementing effective SDM tools. The aim of this study is to affirm core elements of SDM in the context of clinical interactions, through a Delphi consensus process.

METHODS: A Delphi was conducted with 30 participants (10 women aged 40-49, 10 PCPs, and 10 healthcare decision scientists), to codify core elements of breast cancer screening SDM. The criterion for establishing consensus was a threshold of $80 \%$ agreement. The Delphi concluded with an $83 \%$ response rate.

RESULTS: Of 48 items fielded, 44 met the threshold on the high-importance end of the response scale and were accepted as core elements. Core elements across three thematic categories-information delivery and patient education, interpersonal clinician-patient communication, and framework of the decision-received panelists' support in nearly equal measure. Panelists unanimously agreed that SDM should include provision of clearly understandable information, including that of personal breast cancer risk factors, and benefits and harms of mammography screening, and that PCPs should convey they are listening, knowledgeable, and demonstrate cultural sensitivity.

DISCUSSION: This research codifies the core elements of SDM for mammography in women 40-49, augmenting the evidence to inform discussions between patients and physicians. These core elements of SDM have the potential to operationalize SDM for breast cancer screening in an effort to improve public health outcomes.

KEY WORDS: breast cancer screening; health communication; decisionmaking; mammography; Delphi consensus.

Received November 30, 2018

Revised June 7, 2019

Accepted July 30, 2019

Published online March 19, 2020
J Gen Intern Med 35(6): 1668-77

DOI: $10.1007 / \mathrm{s} 11606-019-05298-8$

(c) Society of General Internal Medicine 2019

\section{INTRODUCTION}

Mammography is an effective tool for breast cancer screening. However, guidelines for women aged 40-49 regarding when to begin screening and how often to be screened are inconsistent. The American Cancer Society recommends average-risk women aged 40-44 receive mammography screening annually "if they wish to do so", ${ }^{1}$ while women aged 45-54 should be screened annually. ${ }^{1}$ The United States Preventive Services Task Force (USPSTF) recommends women aged 40-49 consult with their clinician to arrive at a shared decision about initiation and frequency of mammography screening. ${ }^{2,3}$ According to the Informed Medical Decisions Foundation, shared decision-making (SDM) is a collaborative process by which patients and their providers take into account the best evidence available, as well as patients' values and preferences, to make healthcare decisions together. ${ }^{4}$

Models of $\mathrm{SDM}^{5-8}$ highlight the importance of patients understanding they have a choice, discussing alternatives along with the benefits and harms of each alternative (as well as uncertainties), assessing the patient's understanding of the information presented, and exploring their personal preferences. Yet, several studies that examined data from a largescale national survey of adults who made a breast, prostate, or colorectal cancer screening decision revealed considerable deficits in SDM, particularly in breast cancer screening. ${ }^{9-12}$ In comparison with prostate and colorectal screening, patients offered breast cancer screening were least likely to believe they had a choice, ${ }^{9}$ and least reported that their clinician discussed benefits or harms of screening, ${ }^{10,11}$ elicited their input in the decision-making process, ${ }^{10}$ solicited their preferences, ${ }^{12}$ or asked if they wanted to be tested for (breast)cancer. ${ }^{11}$ Overall mean decision processing scores are low for cancer screening, but lowest for mammography. ${ }^{11}$ Furthermore, clinicians report a lack of confidence and knowledge regarding individual breast cancer risk assessment, and 
time constraints as barriers to SDM. ${ }^{13}$ This suggests a critical need for specific and effective guidance in breast cancer screening SDM.

To address this missing guidance, this study sits within a broader research program that is developing a breast cancer screening SDM tool. The aim of this study is to affirm the core elements of SDM for clinical interactions addressing breast cancer screening. Toward this aim, we sought stakeholder consensus on important elements of SDM when considering breast cancer screening. We conducted a Delphi survey with three expert panels: women aged 40-49, primary care providers (PCPs), and healthcare decision scientists (HDSs). The University of Wisconsin Health Sciences Institutional Review Board (IRB) determined the Delphi protocol to be exempt from IRB review.

\section{MATERIALS AND METHODS}

\section{Use of the Delphi Technique}

The Delphi process is a method that facilitates consensus on complex issues. ${ }^{14}$ The Delphi technique implements at least two rounds of a survey and allows participants to modify responses from one round to the next based on participant feedback. Participants in the Delphi technique are anonymous to each other to avoid feeling pressured by other participants to respond in a certain way. We established a foundation for this Delphi procedure by conducting a literature review prior to the survey, to identify the initial range of concepts. ${ }^{15,}{ }^{16}$ Reducing participant burden in this way is believed to have a positive effect on participation. ${ }^{15}$

\section{Selection and Recruitment of Panel Members}

The Delphi survey targeted three expert panels: women aged 40-49, PCPs, and HDSs. Multiple participant types were included to "enrich results of the Delphi procedure." 14 Ten participants were recruited to each panel for a total of 30 participants.

The panel of women aged 40-49 were recruited from an established Patient Advisory Council (PAC) aligned with a breast cancer screening shared decision-making project. The PAC included women with varying screening mammography experiences. PAC members were not exposed to the Delphi prior to survey implementation. The PCPs participating in the Delphi survey are clinicians from the University of Wisconsin School of Medicine and Public Health Departments of Family Medicine and Community Health, General Internal Medicine, and Obstetrics and Gynecology. The panel of women aged 40-49 and the PCP panelists are based in or around Madison, WI. The panel of HDSs, all with expertise in the fields of medical decision-making, (breast)cancer screening, and communication of health risk information, was recruited from across the USA. Women aged 40-49 and PCPs were paid $\$ 30$ for participation in the first round of the survey and $\$ 50$ in subsequent rounds. The HDSs were not offered a monetary incentive to participate.

\section{Development of Items for Round One of the Delphi Survey}

The content for round one of the Delphi survey was derived from our previously published scoping literature review (see DuBenske et al. for methodological details and findings). ${ }^{17}$ Briefly, this review extracted original articles and editorials addressing empirical evidence reporting on breast cancer screening, medical decision-making, and patient centered care. Reviewers extracted critical findings related to breast cancer screening SDM elements (e.g., structural components, processes, and delivery modes). Content analysis included the development of a thematic categorization schema based on the nature of issues addressed by the extracted SDM elements. This schema included the following three categories: information delivery and patient education (ID), interpersonal clinician-patient communication (COM), and framework of the decision (FD). ID addresses the nature and delivery format of the content provided to the patient or clinician. COM includes characteristics about the patient-clinician relationship and interpersonal interaction. FD addresses the broader framework of the patient and clinician such as personal beliefs, values, and understandings about mammography decisionmaking. Table 1 reports the number of items in all survey rounds in each thematic category.

The key elements gathered from the scoping review were formulated into survey items by the lead author $(\mathrm{KC})$. This document was presented to a working group (LD, SS, EB), who screened items ensuring comprehensibility, alignment with concepts identified by the scoping review, and formatting consistency. Explicit steps were taken to insure clarity of survey items for the patient panelist by vetting sections of the Delphi survey with members of a patient advisory committee (PAC). This "patient screening committee" was separate from the PAC from which the Delphi patient panel was recruited.

In order to provide a consistent framework for panelists to respond to, the survey presented an operational definition of SDM adapted from the Informed Medical Decisions

Table 1 Scoping Literature Review Thematic Category Item Counts in All Survey Rounds

\begin{tabular}{llll}
\hline \hline Thematic categories & $\begin{array}{l}\text { Round 1 } \\
\text { no. of items }\end{array}$ & $\begin{array}{l}\text { Round 2 } \\
\text { no. of items }\end{array}$ & $\begin{array}{l}\text { Round 3 } \\
\text { no. of items }\end{array}$ \\
\hline $\begin{array}{l}\text { Information delivery/ } \\
\text { patient education }\end{array}$ & 19 & 11 & 2 \\
$\begin{array}{l}\text { Interpersonal clinician- } \\
\text { patient communication }\end{array}$ & 4 & 5 & 0 \\
$\begin{array}{l}\text { Framework of the } \\
\text { decision }\end{array}$ & 10 & 6 & 0 \\
$\quad$ Total & $33 *$ & 22 & 2 \\
\hline
\end{tabular}

*There were 32 Likert-type items in round one. However, one item counts twice in this table because it was assigned to two thematic categories 
Foundation. ${ }^{4}$ Panel participants were instructed to respond to survey items referencing this "standard" definition for SDM.

\section{Overview of Survey Rounds}

The Delphi survey was conducted over three rounds, from July to November 2017 (see Fig. 1 for overview). Panelists rated the importance of each item to achieving SDM between women aged 40-49 and their PCP when considering mammography for breast cancer screening. The same 5-point response scale was offered for all items: not at all important, slightly important, somewhat important, very important, and extremely important.

Round one consisted of 32 Likert-type items from the literature review ${ }^{17}$ and five open-ended items for panelists to suggest new items for round two. Round one panelists suggested 48 new items for round two. Inclusion/exclusion criteria for new items in round two were based on comparative language processes. A suggested item was excluded if it contained language identical to or synonymous with language encapsulated within literature-derived items. Similarly, suggested items that contained identical or synonymous language were combined to develop one item. General comments not intended to be a new item (i.e., recommendations for future studies) were eliminated. Inclusion/exclusion criteria were applied comparatively by individual authors (KC, TL). Of the 48 suggestions, 16 were created and added to round two as new Likert-type items.

For re-fielded items, panelists were shown their individual responses as well as all panelists' aggregated responses from the previous round. Panelists were instructed that they were free to change their response or respond the same way they did in the previous round and reminded that their responses would remain confidential.

All rounds of the survey were fielded online, using Qualtrics software (July 2017). Panelists were sent an email containing an individualized link to the surveys. Reminder emails were sent to non-responders.

\section{Consensus Criteria}

Criteria for establishing consensus after Delphi rounds vary considerably by the topic and complexity of the issue. ${ }^{18}$ A 70 $80 \%$ consensus threshold is typical among groups likely to disagree such as advocates and opponents of an issue, perhaps higher among more homogeneous respondents. ${ }^{19}, 20$

Because our Delphi items were based on an extensive literature review on SDM, we expected a fairly high level of consensus and set the threshold at $80 \%$ agreement. This threshold was applied in the following way: we combined the two low-importance responses (not at all/slightly important) into one group and the two high-importance responses (very/extremely important) into another group. If at least $80 \%$ of panelists selected either not at all/slightly important or very/ extremely important, the item was considered as having consensus and was not re-fielded in a subsequent survey round.
Further, if the consensus fell on the high-importance end of the scale (very/extremely important), the item was deemed to be a core element of SDM in clinical consultations addressing breast cancer screening.

For any item failing to achieve consensus on either the highor low-importance ends of the scale over two consecutive rounds, a Spearman's rank correlation coefficient was calculated to determine the strength of the correlation between the two rounds' responses. A strong positive Spearman's correlation $(\alpha=0.05, r>0.829)$ between the responses to an item over two rounds, indicating responses did not change significantly between rounds, triggered the termination of the item from the survey because of the low likelihood that it would achieve consensus in a later round. ${ }^{21}$

\section{RESULTS}

Of the 30 individuals who agreed to participate in round one, 27 completed the survey. Round two of the survey was sent to 27 individuals, 25 of whom completed the survey. Of the 25 individuals who were sent round three of the survey, all 25 completed the survey.

Of the 48 total Likert-type items fielded in at least one round of the Delphi survey, 44 items exceeded the $80 \%$ threshold on the high-importance end of the response scale and were accepted as core elements of SDM for breast cancer screening. All 44 consensus items deemed to be core elements of SDM for breast cancer screening are shown in Tables 2, 3, and 4, grouped according to their thematic category. Table 5 draws attention to items that achieved unanimous $(100 \%)$ consensus in their rating of high importance.

Of the 48 Likert-type items fielded in at least one round of the Delphi survey, four items failed to achieve consensus and were therefore rejected as core elements of SDM for breast cancer screening (Table 6). Because all items achieved a final disposition by the end of round three, a fourth round of the survey was not required.

\section{Information Delivery and Patient Education}

Twenty-two of the 25 ID items were retained as core SDM elements. Stakeholders endorsed the importance that PCPs inform patients that their risk for breast cancer is based on personal risk factors, explain and identify these risk factors, and how their personal breast cancer risk compares to the general population. Furthermore, core elements of SDM include telling a woman the benefits and harms of screening mammography as well as the alternatives to mammography (e.g., not screening), and that these risks include uncertainties. Information should also be presented utilizing evidence-based effective language, statistics, and graphic presentations. To appropriately engage with all women, information should be presented in multiple languages and use images and examples for all women to feel represented and that the information applies to them. Furthermore, due to ever-changing 


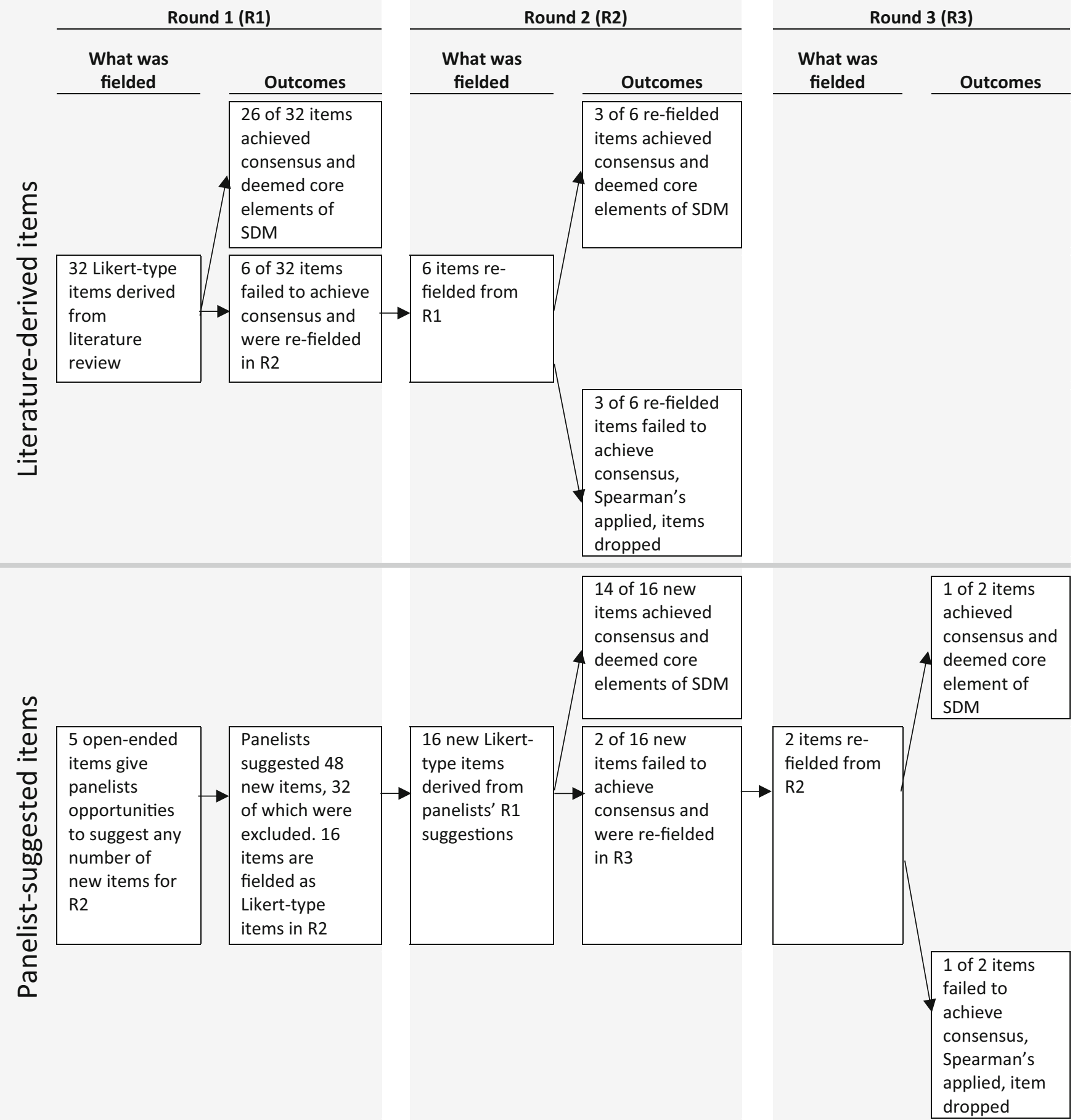

Figure 1 Schema for survey rounds.

professional guidelines and recommendations, PCPs should recommend having discussions about breast cancer screening on a regular basis. Finally, the healthcare system should ensure access to breast cancer screening information before and after the clinical encounter and make point-of-care decision aids easily accessible for clinicians to utilize with patients.

\section{Interpersonal Clinician-Patient Communication}

All nine COM items were retained as SDM core elements. Stakeholder consensus demonstrated the importance that PCPs present information about breast cancer screening in the most clear and understandable way and assess patient 
Table 2 Items That Achieved Consensus in Round 1 and Were Deemed Core Elements of SDM for Breast Cancer Screening. Each Cell Shows Percentage and Number (in Parentheses) of Panelists That Selected Either Very or Extremely Important

\begin{tabular}{|c|c|c|c|c|}
\hline Item & Women 40-49 & PCPs & HDSs & Total \\
\hline \multicolumn{5}{|c|}{ a. Items that achieved consensus aligned with the theme information delivery and patient education (ID) } \\
\hline $\begin{array}{l}\text { PCPs should tell women that their risk of breast cancer is based on their } \\
\text { personal risk factors. }\end{array}$ & $100 \%(10 / 10)$ & $100 \%(10 / 10)$ & $100 \%(7 / 7)$ & $100 \%(27 / 27)$ \\
\hline PCPs should identify and explain a woman's personal breast cancer risk factors. & $100 \%(10 / 10)$ & $100 \%(10 / 10)$ & $100 \%(7 / 7)$ & $100 \%(27 / 27)$ \\
\hline $\begin{array}{l}\text { PCPs should correct any misunderstandings a woman may have about } \\
\text { information they provide about mammography for breast cancer screening. }\end{array}$ & & $100 \%(27 / 27)$ \\
\hline PCPs should tell a woman the benefits of having mammography screening. & $100 \%(10 / 10)$ & $100 \%(10 / 10)$ & $100 \%(7 / 7)$ & $100 \%(27 / 27)$ \\
\hline PCPs should tell a woman the risks of having mammography screening. & $100 \%(10 / 10)$ & $100 \%(10 / 10)$ & $100 \%(7 / 7)$ & $100 \%(27 / 27)$ \\
\hline $\begin{array}{l}\text { PCPs should tell women that screening could reduce the risk of negative } \\
\text { outcomes (cancer getting worse, death) if they develop breast cancer by giving } \\
\text { them options to seek treatment. }\end{array}$ & $100 \%(10 / 10)$ & $90 \%(9 / 10)$ & $100 \%(7 / 7)$ & $96.3 \%(26 / 27)$ \\
\hline $\begin{array}{l}\text { PCPs should tell women that not screening could increase the risk of negative } \\
\text { outcomes (cancer getting worse, death) if they develop breast cancer. }\end{array}$ & $90 \%(9 / 10)$ & $100 \%(10 / 10)$ & $100 \%(7 / 7)$ & $96.3 \%(26 / 27)$ \\
\hline $\begin{array}{l}\text { PCPs should explain that information relating to risk has uncertainties and is not } \\
\text { a guarantee. }\end{array}$ & $70 \%(7 / 10)$ & $100 \%(10 / 10)$ & $100 \%(7 / 7)$ & $88.9 \%(24 / 27)$ \\
\hline PCPs should tell a woman the benefits of not having mammography screening. & 80 & 90 & ? & 24/27) \\
\hline $\begin{array}{l}\text { Healthcare systems should use language and word choice when presenting } \\
\text { information about mammography and breast cancer risk that research has shown } \\
\text { to be the most effective for aiding women's understanding. }\end{array}$ & & $80^{c}$ & $100 \%(7 / 7)$ & $88.9 \%(24 / 27)$ \\
\hline $\begin{array}{l}\text { PCPs should present both sides of the decision to have mammography or not } \\
\text { and not try to persuade. }\end{array}$ & $80 \%(8 / 10)$ & $100 \%(10 / 10)$ & $86 \%(6 / 7)$ & $88.9 \%(24 / 27)$ \\
\hline woman the risks of not having mammography screening. & ) & 1( & 7) & 7) \\
\hline nammography & 10) & 10) & 6/7) & $(24 / 27)$ \\
\hline PCPs s & & & $6(6 / 7)$ & $85.2 \%(23 / 27)$ \\
\hline $\begin{array}{l}\text { Healthcare systems should present statistics regarding mammography and breast } \\
\text { cancer risk in a manner that research has shown to be the most effective for } \\
\text { aiding women's understanding. }\end{array}$ & $90 \%$ & $60^{c}$ & $100 \%(7 / 7)$ & $81.5 \%(22 / 27)$ \\
\hline \multicolumn{5}{|c|}{ b. Items that achieved consensus aligned with the theme interpersonal clinician-patient communication (COM) } \\
\hline $\begin{array}{l}\text { PCPs should present information regarding mammography and breast cancer in } \\
\text { the most clear and understandable way. }\end{array}$ & $100 \%(10 / 10)$ & $100 \%(10 / 10)$ & $100 \%(7 / 7)$ & $100 \%(27 / 27)$ \\
\hline $\begin{array}{l}\text { PCPs should check with a woman to make sure she understands the } \\
\text { information. }\end{array}$ & $90 \%(9 / 10)$ & 100 & $100 \%(7 / 7)$ & 96.3 \\
\hline uld express genuine & & & & $6 / 27)$ \\
\hline $\begin{array}{l}\text { PCPs should present both sides of the decision to have mammography or not } \\
\text { and not try to persuade. }\end{array}$ & $80 \%$ & 100 & $86^{\circ}$ & $(24 / 27)$ \\
\hline \multicolumn{5}{|c|}{ c. Items that achieved consensus aligned with the theme of framework of the decision (FD) } \\
\hline PCPs should act with sensitivity to cultural beliefs and behaviors & $100 \%(10 / 10)$ & $100 \%(10 / 10)$ & $100 \%(7 / 7)$ & $100 \%(27 / 27)$ \\
\hline $\begin{array}{l}\text { PCPs should tell women there is a decision to make about breast cancer } \\
\text { screening. }\end{array}$ & $90 \%(9 / 10)$ & $100 \%(10 / 10)$ & $100 \%(7 / 7)$ & $96.3 \%(26 / 27)$ \\
\hline PCPs and women should discuss a woman's role in decision-making. & & & & $96.3 \%(26 / 27)$ \\
\hline $\begin{array}{l}\text { PCPs and women should discuss a woman's values with regard to a screening } \\
\text { mammogram. }\end{array}$ & 7/10) & 100 & $100 \%(7 / 7)$ & $88.9 \%(24 / 27)$ \\
\hline $\begin{array}{l}\text { PCPs and women should discuss a woman's preferences with regard to a } \\
\text { screening mammogram. }\end{array}$ & $70 \%(7 / 10)$ & $100 \%(10 / 10)$ & $100 \%(7 / 7)$ & $88.9 \%(24 / 27)$ \\
\hline $\begin{array}{l}\text { PCPs should accept that a woman's informed decision on her own care may not } \\
\text { necessarily be one that reduces risk. }\end{array}$ & $70 \%(7 / 10)$ & $100 \%(10 / 10)$ & $100 \%(7 / 7)$ & $88.9 \%(24 / 27)$ \\
\hline $\begin{array}{l}\text { PCPs and women should discuss the nature of the decision to be made (whether } \\
\text { and how often to use mammography for breast cancer screening). }\end{array}$ & $80^{\circ}$ & 3/10) & $100 \%(7 / 7)$ & 85. \\
\hline $\begin{array}{l}\text { PCPs and women should discuss a woman's personal values and preferences in } \\
\text { general. }\end{array}$ & $70 \%(7 / 10)$ & $100 \%(10 / 10)$ & $86 \%(6 / 7)$ & $85.2 \%(23 / 27)$ \\
\hline
\end{tabular}

understanding, and that the healthcare system should offer PCPs training in doing so. Furthermore, PCPs can facilitate SDM through demonstrating their genuine caring and concern, and that they are listening and knowledgeable. Core SDM elements in breast cancer screening should include helping the patient decide at what age to initiate and how often to conduct screening. Overall, PCPs should communicate without persuasion.

\section{Framework of the Decision}

Thirteen of the 14 FD items were retained as core SDM elements. PCPs need to set up a framework for SDM that includes informing the patient there is a decision to make, describing the nature of the decision and discussing the patient's role in this process. SDM should include discussion of the patient's relevant values and preferences in general and specific to breast cancer screening. PCPs should be sensitive to a patient's cultural beliefs and behaviors, as well as logistical and cost factors that impact decision-making regarding breast cancer screening. Furthermore, the healthcare system needs to encourage patients to be assertive in communicating with their PCP, and PCPs need to accept that a woman's informed decision may not be the one that reduces risk. Additionally, workflow practices need to afford PCPs time for engaging in SDM and a means of documenting a patient's values, preferences, and decision. 
Table 3 Items That Achieved Consensus in Round 2 and Were Deemed Core Elements of SDM for Breast Cancer Screening. Each Cell Shows Percentage and Number (in Parentheses) of Panelists That Selected Either Very or Extremely Important

\begin{tabular}{|c|c|c|c|c|c|c|c|c|}
\hline \multirow[b]{2}{*}{ Item } & \multicolumn{4}{|l|}{ Round 1} & \multicolumn{4}{|l|}{ Round 2} \\
\hline & $\begin{array}{l}\text { Women } \\
40-49\end{array}$ & PCPs & HDSs & Total & $\begin{array}{l}\text { Women } \\
40-49\end{array}$ & PCPs & HDSs & Total \\
\hline \multicolumn{9}{|c|}{ a. Items that achieved consensus aligned with the theme information delivery and patient education (ID) } \\
\hline $\begin{array}{l}\text { Healthcare systems should ensure women have } \\
\text { access to the amount of information about } \\
\text { mammography screening that they want, both } \\
\text { before and after clinic visits. }\end{array}$ & & & & & $\begin{array}{l}90 \% \\
(9 / 10)\end{array}$ & $\begin{array}{l}100 \% \\
(10 / 10)\end{array}$ & $\begin{array}{l}100 \% \\
(5 / 5)\end{array}$ & $\begin{array}{l}96 \% \\
(24 / 25)\end{array}$ \\
\hline $\begin{array}{l}\text { Healthcare systems should make point-of-care } \\
\text { decision aids easily accessible for clinicians to use } \\
\text { with women during consultations about mammog- } \\
\text { raphy screening. }\end{array}$ & & & & & $\begin{array}{l}90 \% \\
(9 / 10)\end{array}$ & $\begin{array}{l}90 \% \\
(9 / 10)\end{array}$ & $\begin{array}{l}100 \% \\
(5 / 5)\end{array}$ & $\begin{array}{l}92 \% \\
(23 / 25)\end{array}$ \\
\hline $\begin{array}{l}\text { Healthcare systems should use graphic } \\
\text { representations regarding mammography and breast } \\
\text { cancer risk that research has shown to be the most } \\
\text { effective for aiding women's understanding. }\end{array}$ & $\begin{array}{l}60 \% \\
(6 / 10)\end{array}$ & $\begin{array}{l}70 \% \\
(7 / 10)\end{array}$ & $\begin{array}{l}100 \% \\
(7 / 7)\end{array}$ & $\begin{array}{l}74 \% \\
(20 / 27)\end{array}$ & $\begin{array}{l}100 \% \\
(10 / 10)\end{array}$ & $\begin{array}{l}80 \% \\
(8 / 10)\end{array}$ & $\begin{array}{l}100 \% \\
(5 / 5)\end{array}$ & $\begin{array}{l}92 \% \\
(23 / 25)\end{array}$ \\
\hline $\begin{array}{l}\text { Healthcare systems should present images and } \\
\text { information about screening mammography and } \\
\text { breast cancer risk in ways that women from all } \\
\text { walks of life can see themselves in the images and } \\
\text { feel the information applies to them. }\end{array}$ & & & & & $\begin{array}{l}90 \% \\
(9 / 10)\end{array}$ & $\begin{array}{l}90 \% \\
(9 / 10)\end{array}$ & $\begin{array}{l}100 \% \\
(5 / 5)\end{array}$ & $\begin{array}{l}92 \% \\
(23 / 25)\end{array}$ \\
\hline $\begin{array}{l}\text { Healthcare systems should make information } \\
\text { regarding mammography for breast cancer } \\
\text { screening available in multiple languages. }\end{array}$ & & & & & $\begin{array}{l}100 \% \\
(10 / 10)\end{array}$ & $\begin{array}{l}100 \% \\
(10 / 10)\end{array}$ & $\begin{array}{l}60 \% \\
(3 / 5)\end{array}$ & $\begin{array}{l}92 \% \\
(23 / 25)\end{array}$ \\
\hline $\begin{array}{l}\text { PCPs should tell women how their personal risk of } \\
\text { breast cancer compares to the general population. } \\
\text { Because expert groups such as the US Preventive } \\
\text { Services Task Force and the American Cancer }\end{array}$ & $\begin{array}{l}40 \% \\
(4 / 10)\end{array}$ & $\begin{array}{l}80 \% \\
(8 / 10)\end{array}$ & $\begin{array}{l}86 \% \\
(6 / 7)\end{array}$ & $\begin{array}{l}66.7 \% \\
(18 / 27)\end{array}$ & $\begin{array}{l}70 \% \\
(7 / 10) \\
80 \% \\
(8 / 10)\end{array}$ & $\begin{array}{l}90 \% \\
(9 / 10) \\
70 \% \\
(7 / 10)\end{array}$ & $\begin{array}{l}100 \% \\
(5 / 5) \\
100 \% \\
(5 / 5)\end{array}$ & $\begin{array}{l}84 \% \\
(21 / 25) \\
80 \% \\
(20 / 25)\end{array}$ \\
\hline
\end{tabular}

Society change their recommendations on what age

to begin mammography screening and how

frequently to be screened over time, PCPs should

recommend that women discuss the decision about

whether to have mammography screening with their

PCPs on a regular basis.

b. Items that achieved consensus aligned with the theme interpersonal clinician-patient communication (COM)

PCPs should show a woman they are listening.

PCPs should show a woman they are

knowledgeable.

PCPs should help a woman decide at what age to

begin screening.

PCPs should help a woman decide how often to

get screened.

Healthcare systems should train PCPs to provide

clear explanations to women about the risks and

benefits of mammography screening.

c. Items that achieved consensus aligned with the theme of framework of the decision (FD)

Healthcare systems should have workflow

practices that allow PCPs to spend enough time

with women in clinic visits.

Healthcare systems should encourage women to be

assertive when they communicate with their PCP.

PCPs should recognize that logistical issues such

as taking time off work and traveling to a clinic for

screening may factor in to a woman's decision to

get screened.

PCPs should recognize that a woman's ability to afford mammography screening may factor in to her decision to get screened.

Healthcare systems should have workflow practices that allow PCPs to document women's values and preferences and their decision about whether to have mammography screening.

\begin{tabular}{|c|c|c|c|c|c|c|c|}
\hline & & & & $\begin{array}{l}100 \% \\
(10 / 10)\end{array}$ & $\begin{array}{l}100 \% \\
(10 / 10)\end{array}$ & $\begin{array}{l}80 \% \\
(4 / 5)\end{array}$ & $\begin{array}{l}96 \% \\
(24 / 25\end{array}$ \\
\hline \multirow[t]{3}{*}{$\begin{array}{l}90 \% \\
(9 / 10)\end{array}$} & $\begin{array}{l}60 \% \\
(6 / 10)\end{array}$ & $\begin{array}{l}86 \% \\
(6 / 7)\end{array}$ & $\begin{array}{l}77.8 \% \\
(21 / 27)\end{array}$ & $\begin{array}{l}100 \% \\
(10 / 10) \\
70 \% \\
(7 / 10)\end{array}$ & $\begin{array}{l}80 \% \\
(8 / 10) \\
90 \% \\
(9 / 10)\end{array}$ & $\begin{array}{l}100 \% \\
(5 / 5) \\
100 \% \\
(5 / 5)\end{array}$ & $\begin{array}{l}92 \% \\
(23 / 25 \\
84 \% \\
(21 / 25\end{array}$ \\
\hline & & & & $\begin{array}{l}80 \% \\
(8 / 10)\end{array}$ & $\begin{array}{l}90 \% \\
(9 / 10)\end{array}$ & $\begin{array}{l}80 \% \\
(4 / 5)\end{array}$ & $\begin{array}{l}84 \% \\
(21 / 25\end{array}$ \\
\hline & & & & $\begin{array}{l}70 \% \\
(7 / 10)\end{array}$ & $\begin{array}{l}80 \% \\
(8 / 10)\end{array}$ & $\begin{array}{l}100 \% \\
(5 / 5)\end{array}$ & $\begin{array}{l}80 \% \\
(20 / 25\end{array}$ \\
\hline
\end{tabular}

\section{DISCUSSION}

This research has demonstrated a consensus among a panel of women aged 40-49, PCPs, and HDSs on what constitutes SDM in the context of clinical deliberations when contemplating the use of mammography for breast cancer screening.
Forty-four of the 48 items (91.7\%) presented to panelists were accepted as core elements of SDM. Of these 48 items, several achieved unanimous consensus across stakeholder groups. Because of the high overall acceptance rate, all three thematic categories - information delivery and patient education, 
Table 4 Items That Achieved Consensus in Round 3 and Were Deemed Core Elements of SDM for Breast Cancer Screening. Each Cell Shows Percentage and Number (in Parentheses) of Panelists That Selected Either Very or Extremely Important

\begin{tabular}{|c|c|c|c|c|c|c|c|c|c|c|c|c|}
\hline \multirow[b]{2}{*}{ Item (theme) } & \multicolumn{4}{|l|}{ Round 1} & \multicolumn{4}{|l|}{ Round 2} & \multicolumn{4}{|l|}{ Round 3} \\
\hline & $\begin{array}{l}\text { Women } \\
40-49\end{array}$ & PCPs & HDSs & Total & $\begin{array}{l}\text { Women } \\
40-49\end{array}$ & PCPs & HDSs & Total & $\begin{array}{l}\text { Women } \\
40-49\end{array}$ & PCPs & HDSs & Total \\
\hline $\begin{array}{l}\text { PCPs should tell } \\
\text { women that expert } \\
\text { groups such as the US } \\
\text { Preventive Services } \\
\text { Task Force and the } \\
\text { American Cancer } \\
\text { Society differ in their } \\
\text { recommendations on } \\
\text { what age to begin } \\
\text { mammography } \\
\text { screening and how } \\
\text { frequently to be } \\
\text { screened. (information } \\
\text { delivery and patient } \\
\text { education) }\end{array}$ & & & & & $\begin{array}{c}50 \% \\
(5 / 10)\end{array}$ & $\begin{array}{c}80 \% \\
(8 / 10)\end{array}$ & $\begin{array}{l}100 \% \\
(5 / 5)\end{array}$ & $\begin{array}{c}72 \% \\
(18 / 25)\end{array}$ & $\begin{array}{c}80 \% \\
(8 / 10)\end{array}$ & $\begin{array}{c}90 \% \\
(9 / 10)\end{array}$ & $\begin{array}{l}100 \% \\
(5 / 5)\end{array}$ & $\begin{array}{c}88 \% \\
(22 / 25)\end{array}$ \\
\hline
\end{tabular}

interpersonal clinician-patient communication, and framework of the decision - received the support of our panelists in nearly equal measure.

Our research begins to provide the guidance missing from the USPSTF recommendation to use SDM to help women decide about screening mammography in their 40s. A large portion of the items accepted by our panelists as core elements of SDM (29 of 44) were derived from a scientific literature review. ${ }^{17}$ Our panelists have therefore affirmed SDM principles as found in the literature. In addition, by inviting panelists to suggest items for other panelists to consider, and by achieving consensus on those suggested items in subsequent rounds, our panelists identified several core elements of SDM not found in the empirical literature, spanning across the thematic categories of information delivery and patient education, framework of the decision, and interpersonal clinicianpatient communication.

As summarized in the "INTRODUCTION" section, research has demonstrated the shortcomings in shared decision-making in cancer screening, particularly for breast cancer. $^{9-12,22-24}$ Each of these shortcomings was represented in our study by an identified core element for breast cancer SDM: PCPs should tell patients they have a choice; PCPs should tell patients about the risks and benefits of screening, as well as for alternatives; and PCPs should discuss the patient's values and preferences. Clinician concerns identified in our earlier research ${ }^{13}$ were represented by identified SDM core elements that the healthcare system should have workflow practices that allow PCPs enough time with patients, should train PCPs to provide clear explanations about risks and benefits of screening options, and have point-of-care decision aids accessible to PCPs to facilitate SDM. This further supports the value of the core elements identified in the study and the critical need for interventions to facilitate SDM at the point of care and within the broader healthcare system.

\section{Practice Implications}

There is an abundance of scientific evidence documenting the effectiveness of SDM as a means to better align clinical knowledge and patient values and preferences when considering breast cancer screening. Many professionals feel underequipped in the face of the complexity of the conversation and do not know how to effectuate SDM within the clinical interaction. ${ }^{25}$ The core elements established by this Delphi will help guide professionals in their effort to support patients in the SDM process of making informed healthcare choices. Box 1 provides a concise summary of the core elements specific to the fundamental role clinicians play in mammography shared decision-making. It also provides a yardstick with which to measure quality of mammography shared deci-

Table 5 Items That Achieved Unanimous (100\%) Consensus for High Importance

\begin{tabular}{|c|c|c|}
\hline Item & Source & Theme \\
\hline PCPs should tell women that their risk of breast cancer is based on their personal risk factors. & Lit & ID \\
\hline PCPs should identify and explain a woman's personal breast cancer risk factors. & Lit & ID \\
\hline $\begin{array}{l}\text { PCPs should correct any misunderstandings a woman may have about information they } \\
\text { provide about mammography for breast cancer screening. }\end{array}$ & Lit & ID \\
\hline PCPs should tell a woman the benefits of having mammography screening. & Lit & ID \\
\hline PCPs should tell a woman the risks of having mammography screening. & Lit & ID \\
\hline $\begin{array}{l}\text { PCPs should present information regarding mammography and breast cancer in the most } \\
\text { clear and understandable way. }\end{array}$ & Lit & $\mathrm{COM}$ \\
\hline PCPs should act with sensitivity to cultural beliefs and behaviors. & Lit & FD \\
\hline PCPs should show a woman they are listening. & Panel (women 40-49) & $\mathrm{COM}$ \\
\hline PCPs should show a woman they are knowledgeable. & Panel (women 40-49) & $\mathrm{COM}$ \\
\hline
\end{tabular}


Table 6 Items That Failed to Achieve Consensus

\begin{tabular}{|c|c|c|c|c|c|c|c|c|c|c|c|c|}
\hline \multirow[b]{2}{*}{ Item (theme) } & \multicolumn{4}{|l|}{ Round 1} & \multicolumn{4}{|l|}{ Round 2} & \multicolumn{4}{|l|}{ Round 3} \\
\hline & $\begin{array}{l}\text { Women } \\
40-49\end{array}$ & PCPs & HDSs & Total & $\begin{array}{l}\text { Women } \\
40-49\end{array}$ & PCPs & HDSs & Total & $\begin{array}{l}\text { Women } \\
40-49\end{array}$ & PCPs & HDSs & Total \\
\hline $\begin{array}{l}\text { PCPs should explain } \\
\text { the process of getting } \\
\text { a screening } \\
\text { mammogram. } \\
\text { (information delivery } \\
\text { and patient } \\
\text { education) }\end{array}$ & $\begin{array}{c}70 \% \\
(7 / 10)\end{array}$ & $\begin{array}{l}70 \% \\
(7 / 10)\end{array}$ & $\begin{array}{l}57 \% \\
(4 / 7)\end{array}$ & $\begin{array}{l}66.7 \% \\
(18 / 27)\end{array}$ & $\begin{array}{l}70 \% \\
(7 / 10)\end{array}$ & $\begin{array}{l}60 \% \\
(6 / 10)\end{array}$ & $\begin{array}{l}100 \% \\
(5 / 5)\end{array}$ & $\begin{array}{l}72 \% \\
(18 / 25)\end{array}$ & & & & \\
\hline $\begin{array}{l}\text { PCPs should avoid } \\
\text { paying too much } \\
\text { attention to data. } \\
\text { (information delivery } \\
\text { and patient } \\
\text { education) }\end{array}$ & $\begin{array}{c}10 \% \\
(1 / 10)\end{array}$ & $\begin{array}{l}30 \% \\
(3 / 10)\end{array}$ & $\begin{array}{l}14 \% \\
(1 / 7)\end{array}$ & $\begin{array}{l}18.5 \% \\
(5 / 27)\end{array}$ & $\begin{array}{l}20 \% \\
(2 / 10)\end{array}$ & $\begin{array}{l}0 \% \\
(0 / 10)\end{array}$ & $\begin{array}{l}0 \% \\
(0 / 5)\end{array}$ & $\begin{array}{l}8 \% \\
(2 / 25)\end{array}$ & & & & \\
\hline $\begin{array}{l}\text { PCPs and women } \\
\text { should discuss the } \\
\text { costs of } \\
\text { mammography } \\
\text { screening. } \\
\text { (information delivery } \\
\text { and patient } \\
\text { education) }\end{array}$ & & & & & $\begin{array}{l}60 \% \\
(6 / 10)\end{array}$ & $\begin{array}{l}50 \% \\
(5 / 10)\end{array}$ & $\begin{array}{l}60 \% \\
(3 / 5)\end{array}$ & $\begin{array}{l}56 \% \\
(14 / 25)\end{array}$ & $\begin{array}{c}70 \% \\
(7 / 10)\end{array}$ & $\begin{array}{c}50 \% \\
(5 / 10)\end{array}$ & $\begin{array}{c}80 \% \\
(4 / 5)\end{array}$ & $\begin{array}{c}64 \% \\
(16 / 25)\end{array}$ \\
\hline $\begin{array}{l}\text { Healthcare systems } \\
\text { should prepare } \\
\text { women for the } \\
\text { discussion with their } \\
\text { PCP before the } \\
\text { appointment. } \\
\text { (framework of the } \\
\text { decision) }\end{array}$ & $\begin{array}{c}70 \% \\
(7 / 10)\end{array}$ & $\begin{array}{l}40 \% \\
(4 / 10)\end{array}$ & $\begin{array}{l}57 \% \\
(4 / 7)\end{array}$ & $\begin{array}{l}55.6 \% \\
(15 / 27)\end{array}$ & $\begin{array}{l}80 \% \\
(8 / 10)\end{array}$ & $\begin{array}{l}50 \% \\
(5 / 10)\end{array}$ & $\begin{array}{l}80 \% \\
(4 / 5)\end{array}$ & $\begin{array}{l}68 \% \\
(17 / 25)\end{array}$ & & & & \\
\hline
\end{tabular}

sion-making, which is important if we are to identify the gaps in clinician delivery of shared decision-making and the training needed to assure quality. One notable challenge in the delivery of quality SDM counseling is the availability of adequate time in a patient visit. The availability of clear guidelines will enable clinicians to streamline the visit and emphasize the most important elements of breast cancer screening SDM.

\section{Box 1 Fundamental roles for clinicians in mammography shared decision-making}

Establish trust and rapport:

- Express genuine care and concern for the woman, show themselves to be knowledgeable, demonstrate good listening, and act with sensitivity to cultural beliefs and behaviors.

Consider personal risk:

- Tell women that their risk of breast cancer is based on their personal risk factors.

- Help women identify their personal breast cancer risk factors and how their risk compares to the general population.

Acknowledge the decision process:

- Inform a woman that experts differ in their recommendations on what age to begin mammography screening and how frequently to be screened.

- Explain to the woman there is a decision to be made about breast cancer screening and discuss her role in decision-making.

Address potential harms and benefits:

- Inform women of the potential benefits and harms of both having and not having mammography screening, including:

(a) screening could reduce the risk of negative outcomes (cancer getting worse, death) if she develops breast cancer by giving her options to seek treatment;

(b) not screening could increase the risk of negative outcomes (cancer getting worse, death) if she develops breast cancer;

(c) the risks of overtreatment.

- Explain that information relating to risk has uncertainties and is not a guarantee.

Provide alternatives:

- Discuss the alternatives to mammography screening.

Clarify information:

- Present information regarding breast cancer screening in the most clear and understandable way.

- Check with a woman to make sure she understands the information and correct any misunderstandings she may have.

Guide timing and frequency of screening:

- Help a woman decide at what age to begin and how often to get screening.

- Discuss this decision on a regular basis because screening recommendations change frequently.

Remain unbiased:

- Be non-persuasive in presenting both sides of the mammography decision and accept that a woman's informed decision may not necessarily be one that reduces risk.

Identify values and preferences:

- Discuss a woman's personal values and preferences in general and regarding screening mammogram.

- Recognize that financial and logistical issues (e.g., taking time off work, need for childcare) may factor in to a woman's decision to get screened. 
This Delphi study highlights both the importance of addressing benefits and harms of mammography and the key role that individual risk assessment has on a woman's choice about breast cancer screening when guidelines conflict. Clinicians can effectively communicate with patients by establishing trust, providing clear information, and remaining unbiased. Remaining unbiased is predicated on the ability to convey benefits and harms of mammography screening, and alternatives to screening, in a clear and factual manner, without adding any persuasive language. Acknowledging a woman's personal values and preferences about cancer screening as well as potential barriers to screening mammography will contribute greatly to an effective shared decision-making conversation. An additional point addresses the actual process of getting screened. Clinicians are advised to acknowledge the actual decision process, potential timing of screening and potential alternatives to mammography screening.

Our Delphi aimed to identify core SDM elements via consensus among three stakeholder groups: women aged 40-49, PCPs, and HDSs. While beyond the scope of the current analysis, it is noteworthy that some items demonstrated stakeholder group discrepancies in endorsement of importance, a phenomenon also clearly shown in the literature. ${ }^{13,26}$ For the majority of these items, the overall outcome to retain or drop the item was consistent with the overall majority. However, one item, "healthcare systems should prepare women for the discussion with their PCP before the appointment," was dropped due to low PCP endorsement despite the majority of panelists' ratings of high importance. These findings warrant further elucidation and consideration for system-level implications, which will be the focus of a separate manuscript.

Our study is similar to research efforts that have used the Delphi technique to identify stakeholder consensus on core elements or features of public health initiatives or health services, including counseling measures to prevent pediatric injuries, ${ }^{27}$ fall prevention programming, ${ }^{28}$ and a framework to evaluate the quality of patient decision aids. ${ }^{29}$ Our study establishes stakeholder consensus for SDM regarding mammography for women in their 40s. In this way, our research builds on literature that has sought to articulate general principles of SDM, ${ }^{30}$ determine the skills required on the part of healthcare practitioners to achieve SDM,${ }^{31,32}$ establish a SDM model for clinical practice, ${ }^{6}$ and provide specific SDM principles to guide clinical discussions about mammography for breast cancer screening.

\section{Strengths and Limitations}

This study has notable strengths. First, invited panelists included equal representation of women aged 40-49, PCPs, and HDSs. This approach was taken to include the viewpoints of key stakeholder groups. However, the downside of this approach was that disagreements within groups were masked and responses between groups were averaged. Second, the Delphi method forms an opportunity for anonymous sharing of opinions and promotes an environment where all voices contribute equally to consensus formation. The disadvantage of the Delphi technique, however, is the possibility of attrition over multiple survey rounds. In our case, only seven of the 10 invited HDSs participated in round one of the survey. Of these seven, only five HDSs participated in survey rounds two and three. HDSs' viewpoints were therefore underrepresented.

Patient and clinician panelists may not be representative of their respective general groups due to their prior affiliation with the project. Their motivation for participation may result from prior interest or bias toward breast cancer screening and/ or shared decision-making. Alternatively, early involvement in the project may have increased their information or potential bias regarding breast cancer screening. Additionally, all of our PCPs and patients were from the Madison, WI, area. Half of the HDSs dropped out of the study, which may limit geographic diversity, thereby causing bias in the results.

Another conceivable weakness is that we asked panelists to rate the criteria considering the "importance" of the criterion for SDM. A more comprehensive study would have considered features such as feasibility and measurability. ${ }^{29,} 33$ This approach was taken in an effort to diminish burden for panelists and thereby increase response rates to the extent possible. ${ }^{15}$

\section{CONCLUSION}

The core elements described in this study are considered essential to advance the goal of operationalizing SDM for breast cancer screening. Several consensus items looked to healthcare systems to support SDM, including information about how to get a mammogram and provision of adequate time in a visit. This concept underscores the idea that SDM has implications beyond the relationship between the patient and clinician. Future research to develop methods to quantify, determine order of prioritization, and understand the plausibility of incorporating these core elements within a clinical interaction can lead to a more comprehensive integration of SDM into breast cancer screening decision support tools.

Corresponding Author: Elizabeth S. Burnside, MD, MPH, MSUniversity of Wisconsin-Madison, School of Medicine and Public Health, Madison,WI, USA (e-mail: eburnside@uwhealth.org).

Funding Information This work was financially supported by the Community-Academic Partnerships core of the University of Wisconsin Institute for Clinical and Translational Research (UW ICTR), grant 9 U54 TR000021 from the National Center for Advancing Translational Sciences (previously grant 1 UL1 RR025011 from the National Center for Research Resources), the National Institutes of Health, National Cancer Institute, grant K24 CA194251, and the University of Wisconsin Carbone Cancer Center, support grant P3O CAO1452O.

\section{Compliance with Ethical Standards:}

Conflict of Interest: The authors declare that they do not have a conflict of interest. 
Disclaimer: The content is solely the responsibility of the authors and does not necessarily represent the official views of the National Institutes of Health or other funders.

\section{REFERENCES}

1. American Cancer Society. History of ACS Recommendations for the Early Detection of Cancer in People Without Symptoms. https://www.cancer. org/healthy/find-cancer-early/cancer-screening-guidelines/chronological-history-of-acs-recommendations.html. Accessed July 3, 2019.

2. Siu AL, Bibbins-Domingo $\mathbf{K}$, Grossman DC, LeFevre ML, U. S. Preventive Services Task Force. Convergence and Divergence Around Breast Cancer Screening. Annals of internal medicine. 2016;164(4):301302.

3. U.S. Preventative Task Force. Screening for breast cancer: U.S. Preventive Services Task Force recommendation statement. Annals of internal medicine. 2009; 151(10):716-726, w-236.

4. Informed Medical Decision Making Foundation. Tools for Providers. 2014; https://innovations.ahrq.gov/qualitytools/informed-medical-decisionsfoundation-tools-providers. Accessed July 3, 2019.

5. Agency for Healthcare Research and Quality. The SHARE approach. https://www.ahrq.gov/professionals/education/curriculum-tools / shareddecisionmaking/index.html. Accessed July 3, 2019.

6. Elwyn G, Frosch D, Thomson R, et al. Shared decision making: a model for clinical practice. J Gen Intern Med. 2012;27(10):1361-1367.

7. Price D. Sharing clinical decisions by discussing evidence with patients. Perm J. 2005;9(2):70-73.

8. Sheridan SL, Harris RP, Woolf SH, Shared Decision-Making Workgroup of the USPSTF. Shared decision making about screening and chemoprevention. a suggested approach from the U.S. Preventive Services Task Force. Am J Prev Med. 2004;26(1):56-66.

9. Barrett B, McKenna P. Communicating benefits and risks of screening for prostate, colon, and breast cancer. Fam Med. 2011;43(4):248-253.

10. Fowler FJ, Jr., Gerstein BS, Barry MJ. How patient centered are medical decisions?: Results of a national survey. JAMA Intern Med 2013;173(13):1215-1221.

11. Hoffman RM, Elmore JG, Fairfield KM, Gerstein BS, Levin CA, Pignone MP. Lack of shared decision making in cancer screening discussions: results from a national survey. Am J Prev Med. 2014;47(3):251-259.

12. Zikmund-Fisher BJ, Couper MP, Singer E, et al. Deficits and variations in patients' experience with making 9 common medical decisions: the DECISIONS survey. Med Decis Making. 2010;30(5 Suppl):85S-95S.

13. DuBenske LL, Schrager S, McDowell H, Wilke LG, Trentham-Dietz A, Burnside ES. Mammography Screening: Gaps in Patient's and Physician's Needs for Shared Decision-Making. Breast J. 2017;23(2):210-214

14. Boulkedid R, Abdoul H, Loustau M, Sibony O, Alberti C. Using and reporting the Delphi method for selecting healthcare quality indicators: a systematic review. PLoS One. 2011;6(6):e20476.

15. Custer R, Scarcella J, Stewart B. The Modified Delphi Technique - A Rotational Modification. Journal of Career and Technical Education. 1999; 15(2):50-58.

16. Kingston AH, Morgan AJ, Jorm AF, et al. Helping someone with problem drug use: a Delphi consensus study of consumers, carers, and clinicians. BMC psychiatry. 2011;11:3.
17. DuBenske LL, Schrager SB, Hitchcock ME, et al. Key Elements of Mammography Shared Decision-Making: a Scoping Review of the Literature. J Gen Intern Med. 2018;33(10):1805-1814.

18. Fink A, Kosecoff $\mathbf{J}$, Chassin M, Brook RH. Consensus methods: characteristics and guidelines for use. Am $J$ Public Health. 1984;74(9):979-983.

19. Garvelink MM, Ter Kuile MM, Louwe LA, Hilders CG, Stiggelbout AM. A Delphi consensus study among patients and clinicians in the Netherlands on the procedure of informing young breast cancer patients about Fertility Preservation. Acta Oncol. 2012;51(8):1062-1069.

20. Henderson C, Jackson C, Slade M, Young AS, Strauss JL. How should we implement psychiatric advance directives? Views of consumers, caregivers, mental health providers and researchers. Adm Policy Ment Health. 2010;37(6):447-458.

21. Kalaian S, Rafa M. Terminating Sequential Delphi Survey Data Collection. Practical Assessment, Research \& Evaluation. 2012;17(5).

22. Berlin L. Point: Mammography, breast cancer, and overdiagnosis: the truth versus the whole truth versus nothing but the truth. $J$ Am Coll Radiol. 2014;11(7):642-647.

23. Forbes LJ, Ramirez AJ, Expert group on Information about Breast S. Offering informed choice about breast screening. $J$ Med Screen 2014;21(4): 194-200.

24. Nekhlyudov L, Braddock CH, 3rd. An approach to enhance communication about screening mammography in primary care. $J$ Womens Health (Larchmt). 2009; 18(9):1403-1412.

25. Gravel $\mathbf{K}$, Legare $\mathbf{F}$, Graham ID. Barriers and facilitators to implementing shared decision-making in clinical practice: a systematic review of health professionals' perceptions. Implement Sci. 2006; 1:16.

26. Davey HM, Barratt AL, Butow PN, Houssami N. The impact of different criteria for selecting information to be provided to women undergoing diagnostic breast tests. Patient education and counseling. 2008;71(1):8694.

27. Cohen LR, Runyan CW, Downs SM, Bowling JM. Pediatric injury prevention counseling priorities. Pediatrics. 1997;99(5):704-710.

28. Mahoney JE, Clemson L, Schlotthauer A, et al. Modified Delph Consensus to Suggest Key Elements of Stepping On Falls Prevention Program. Frontiers in public health. 2017;5:21.

29. Elwyn G, O'Connor A, Stacey D, et al. Developing a quality criteria framework for patient decision aids: online international Delphi consensus process. BMJ (Clinical research ed). 2006;333(7565):417.

30. Makoul G, Clayman ML. An integrative model of shared decision making in medical encounters. Patient education and counseling. 2006;60(3):301312 .

31. Elwyn G, Edwards A, Kinnersley $\mathbf{P}$, Grol R. Shared decision making and the concept of equipoise: the competences of involving patients in healthcare choices. Br J Gen Pract. 2000;50(460):892-899.

32. Towle A, Godolphin W. Framework for teaching and learning informed shared decision making. BMJ (Clinical research ed). 1999;319(7212):766771.

33. Brook RH. Appropriateness: the next frontier. BMJ (Clinical research ed). 1994;308(6923):218-219.

Publisher's Note Springer Nature remains neutral with regard to jurisdictional claims in published maps and institutional affiliations. 